\title{
Dumbbell shaped craniorbital cavernous hemangioma
}

Xingping Qin ${ }^{1,2^{*}+}$, Farhana Akter ${ }^{3,4 \dagger}$, Lingxia Qin ${ }^{5 \dagger}$, Qiurong Xie ${ }^{6}$, Yanfei $\mathrm{Li}^{7}$, Hongkuan Yang ${ }^{8}$, Xin Li ${ }^{9}$, Guo Zhang ${ }^{1}$, Songlin $\mathrm{Wu}^{10^{*}}$ and Renzhong Liu ${ }^{1 *}$

\begin{abstract}
Background: Cavernous hemangioma of the orbit is a benign tumor mostly located behind the eye globe, but it rarely spread into the brain, which is called cerebral cavernous malformation as well, the lesion in the brain is irregular and enlarged blood. Here we report one particular case of craniorbital cavernous hemangioma.

Case presentation: A 53-year-old woman presented with exophthalmos of the right eye and reduced vision. Computerized tomographical (CT) scan showed osteolytic honeycomb radial changes of the outer plate of the skull. A magnetic resonance imaging (MRI) scan was performed to obtain further details. T1-weighted (T1W) imaging showed slightly low signal mixed with small patchy high signal. T2-weighted (T2W) imaging showed uneven high signal. There was obvious enhancement in the middle and no enhancement in the peripheral bars. A surgically manage was performed using a left frontotemporal approach, the tumor excised fully, and the histopathology results revealed a cavernous hemangioma. The patient recovered well in the follow-up. Post-operative CT scan identified the lesion was successfully resected, MRI scan also showed full resection and enhanced signal from the presence of fat.

Conclusions: Craniorbital cavernous hemangioma is uncommon, however within the cranium, they can lead to numerous complications particularly if affecting the visual apparatus. it could be diagnosed by imaging, which CT scan shows osteolytic honeycomb radial changes of the outer plate of the skull, T1W imaging shows slightly low signal mixed with small patchy high signal, T2W imaging shows uneven high signal, it is obvious enhancement in the middle and no enhancement in the peripheral bars. The surgically manage is the ideally treatment when there are some symptoms.
\end{abstract}

Keywords: Craniorbital tumor, Cavernous hemangioma, Orbit, Sphenoid

\footnotetext{
* Correspondence: qxp718@whu.edu.cn; wusonglin@whu.edu.cn;

liurenzhong@whu.edu.cn

${ }^{+}$Xingping Qin, Farhana Akter and Lingxia Qin contributed equally to this work.

'Department of Neurosurgery, Renmin Hospital of Wuhan University, 238 Jiefang Road, Wuhan 430060, Hubei, China

${ }^{10}$ Department of Geriatrics, Renmin Hospital of Wuhan University, Wuhan, China

Full list of author information is available at the end of the article
}

(c) The Author(s). 2020 Open Access This article is licensed under a Creative Commons Attribution 4.0 International License, which permits use, sharing, adaptation, distribution and reproduction in any medium or format, as long as you give appropriate credit to the original author(s) and the source, provide a link to the Creative Commons licence, and indicate if changes were made. The images or other third party material in this article are included in the article's Creative Commons licence, unless indicated otherwise in a credit line to the material. If material is not included in the article's Creative Commons licence and your intended use is not permitted by statutory regulation or exceeds the permitted use, you will need to obtain permission directly from the copyright holder. To view a copy of this licence, visit http://creativecommons.org/licenses/by/4.0/ The Creative Commons Public Domain Dedication waiver (http://creativecommons.org/publicdomain/zero/1.0/) applies to the data made available in this article, unless otherwise stated in a credit line to the data. 

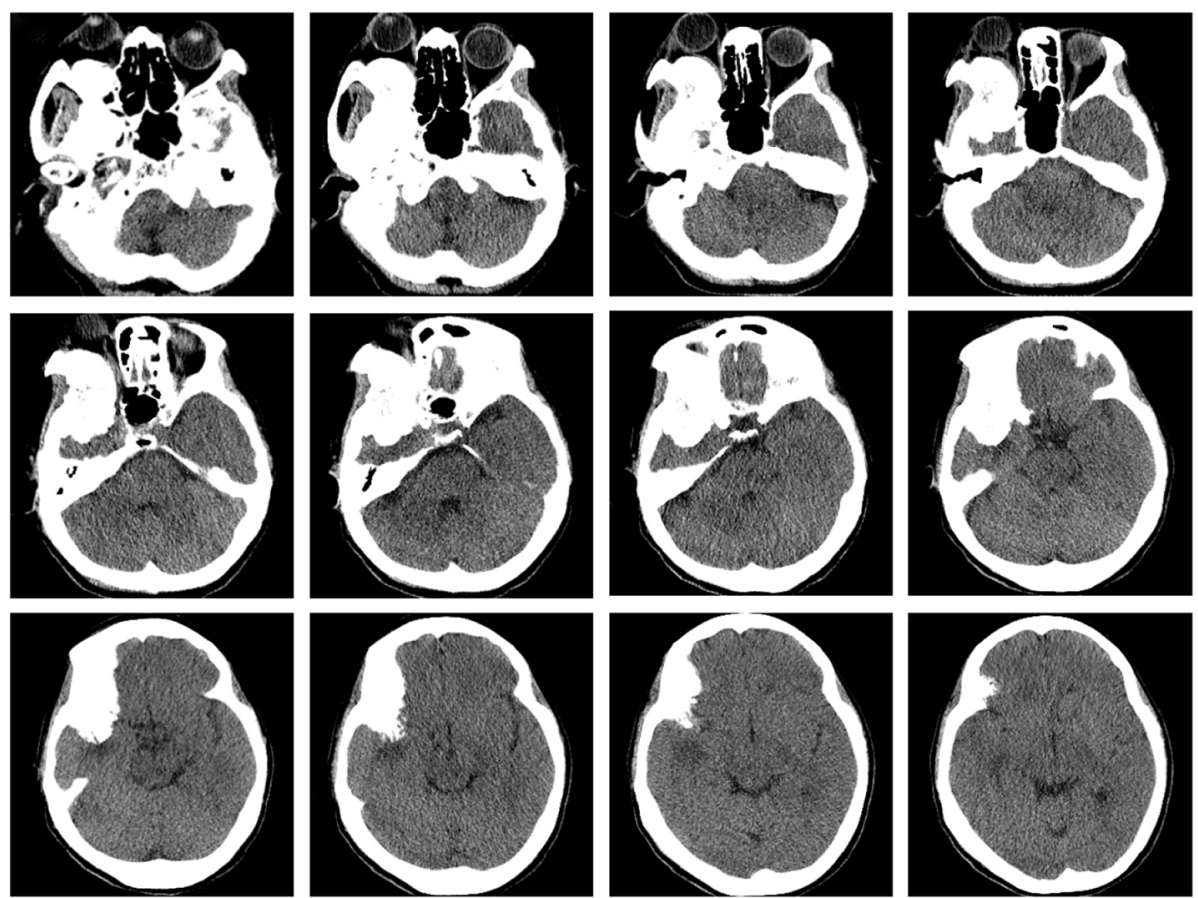

Fig. 1 CT scan showing osteolytic honeycomb changes (arrow). The lesion originates from the right wing of the sphenoid bone, extends to the ipsilateral middle cranial fossa and orbit

\section{Background}

Cavernous hemangioma of the orbit is a benign tumor mostly located behind the eye globe, but it rarely spread into the brain, which is called cerebral cavernous malformation as well, the lesion in the brain is irregular and enlarged blood. Here we report one particular case of craniorbital cavernous hemangioma.

\section{Case presentation}

A 53-year-old female presented to the Ophthalmology department with exophthalmos of the right eye and reduced vision. She was seen by the Ophthalmologist who noted reduced visual acuity in right eye (6/15) compared to the left eye (6/12). Visual field testing revealed a defect in the left upper quadrant of the right eye with
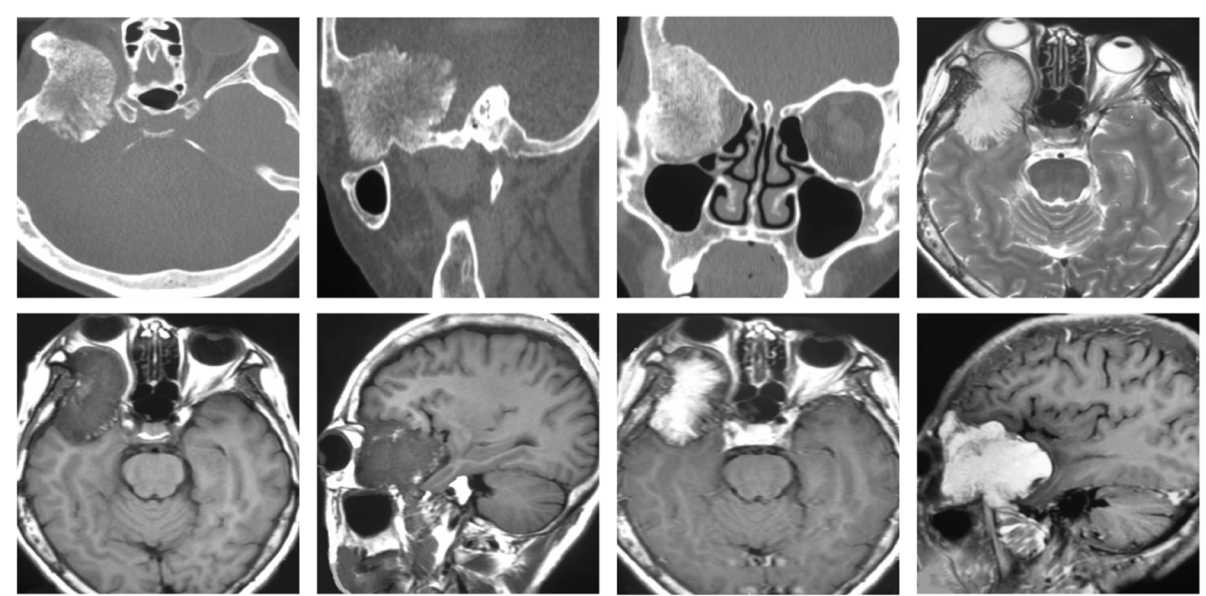

Fig. 2 T1WI showing slightly low signal mixed with small patchy high signal. T2Wl showing uneven high signal. There is enhancement in the center of the lesions but no enhancement in the periphery 
enlargement of the blind spot. Both pupils were however of equal size, diameter of $2.5 \mathrm{~mm}$ and equally reactive to light. The patient was referred for a computerized tomographical (CT) scan, which showed osteolytic honeycomb radial changes of the outer plate of the skull, with external protrusion (Fig. 1). The lesion originated from the right wing of the sphenoid bone, destroyed the outer plate and inner plate, extended to the ipsilateral middle cranial fossa and orbit, and showed a helioradial change. The trabecula of the bone was arranged from the center to the periphery in the shape of chrysanthemum petals. A magnetic resonance imaging (MRI) scan was performed to obtain further details. T1-weighted (T1W) imaging showed slightly low signal mixed with small patchy high signal. T2-weighted (T2W) imaging showed uneven high signal. There was obvious enhancement in the middle and no enhancement in the peripheral bars (Fig. 2). Based on the destructive nature of this lesion, a decision was made to surgically manage this case. Using a left frontotemporal approach, the scalp and temporal muscle were dissected and the right frontotemporal bone flap was removed. The tumor tissue was found to be involving the right superior and lateral wall of the orbit and this was invading the dura matter. The tumor also extended to the right temporal bone and the right skull base. The tumor excised fully and the lesion was sent for histopathology. Free abdominal fat was taken to reconstruct the lateral wall of the orbit. The right frontal temporal bone flap was restored and fixed with cranial locking. Histopathology results revealed a cavernous hemangioma (Fig. 3). A post-operative CT scan showed the lesion was successfully resected (Fig. 4). A postoperative MRI scan also showed full resection and enhanced signal from the presence of fat (Fig. 5). The patient was assessed immediately following the surgery by the operative surgeon. The exophthalmos in her right eye had resolved and the visual field was normal. Follow-up telephone consultation was performed 1 month after the surgery. The patient reported improved vision in the right eye compared to the left eye.

\section{Discussion and conclusions}

Cavernous hemangiomas of the skull are uncommon lesions and represent less than $1 \%$ of bone tumors [1]. Within the skull, they are most commonly located in the frontal bone and are very rarely found in the sphenoid or orbital rim, as seen in this case. Although they are considered benign, they can grow into surrounding tissue and cause localized damage. Hemangiomas are abnormal growth of small blood vessels, which can be classified according to their pathological types. The most common type is capillary hemangioma, which is characterized by a high density of small capillaries lined with a layer of endothelial cells. Cavernous hemangiomas are characterized by high density of large dilated blood vessels with distended 'caverns' filled with blood. Compound hemangiomas are a mixture of both capillary and cavernous. Hemangiomas can also be characterized according to their location and can be found in various organs such as the liver [2]. Hemangiomas can be further characterized as 'congenital', which is present at birth and is very rare or 'infantile', which is present shortly after birth and affects $4-5 \%$ of newborns [3]. Hemangiomas are often confused with vascular malformations, which consists of clusters of blood vessels that develop in particular blood vessels. They are usually more infiltrative than hemangiomas [2].
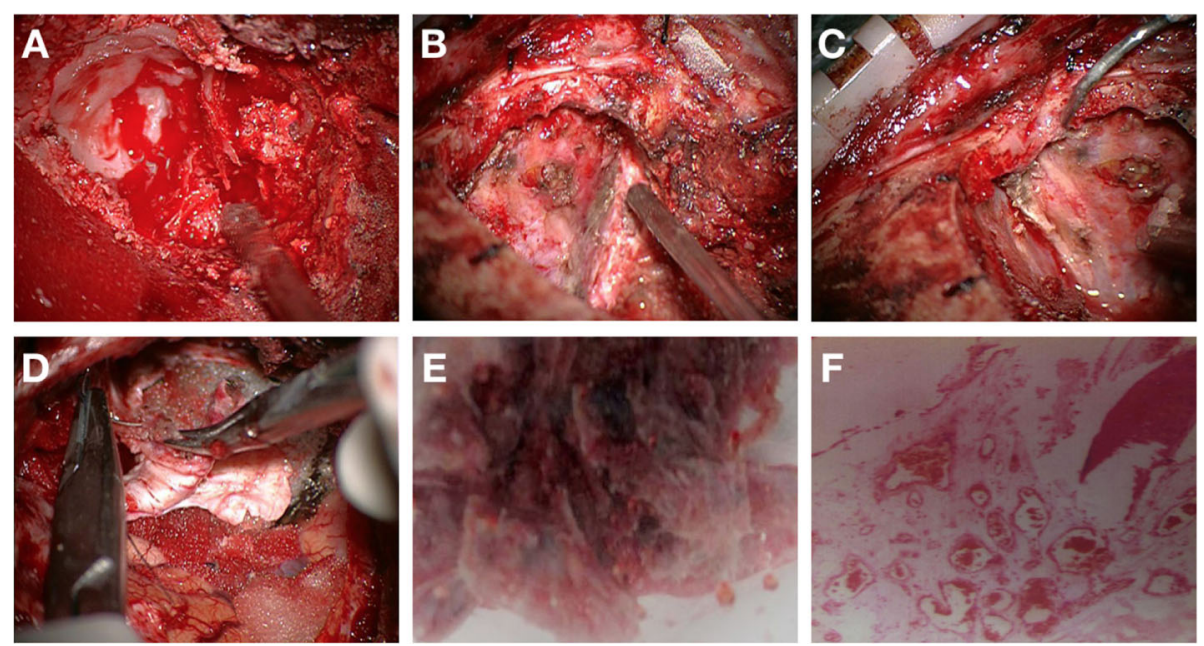

Fig. 3 Resection approach for the tumor affecting the right temporal bone (A-D). Fully resected tumor (E). Histology revealed a cavernous hemangioma (F) 

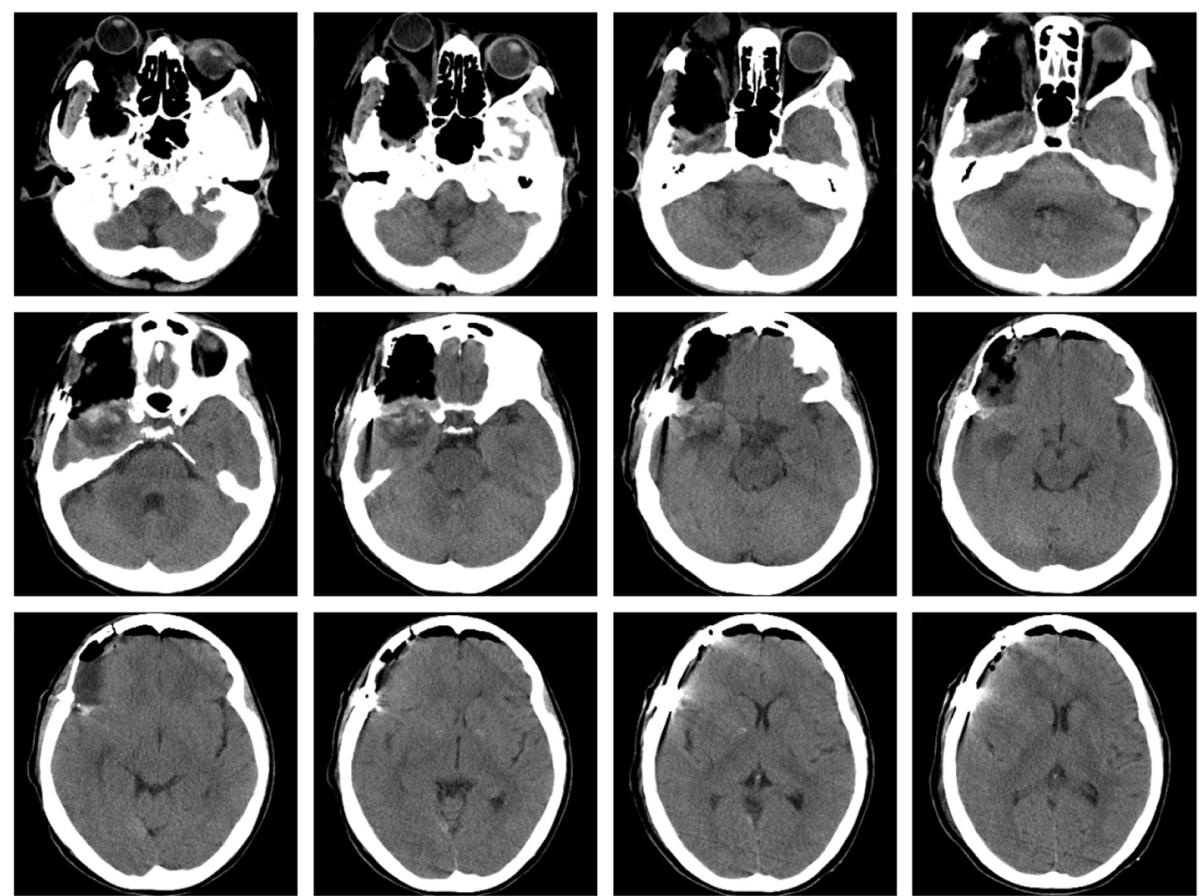

Fig. 4 Post-operative CT scan showing the lesion was successfully resected
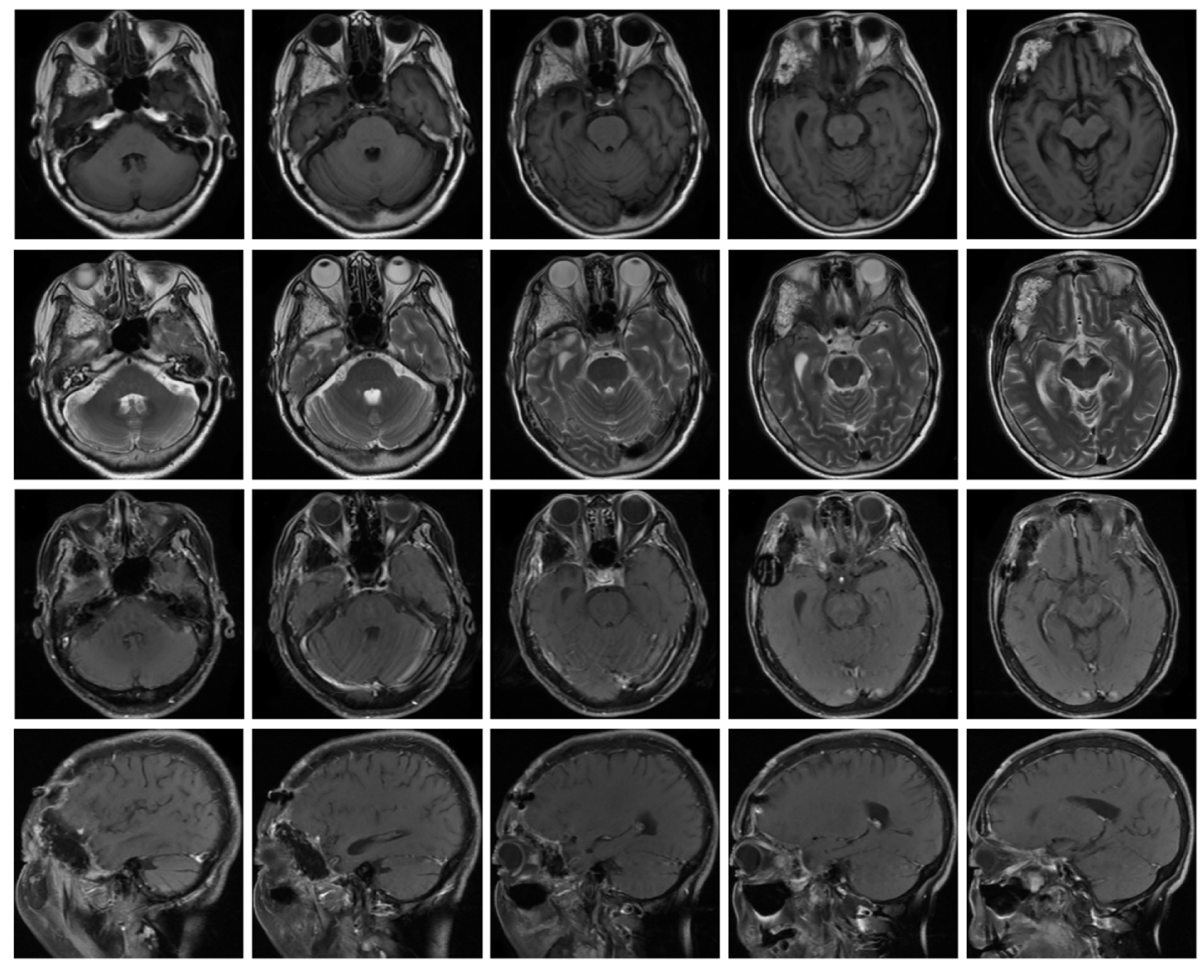

Fig. 5 Post-operative MRI scan also showed full resection and enhanced signal from the presence of fat 
The molecular etiology of this hemangiomas is not well understood. A leading hypothesis is that endothelial cell proliferation and migration is key to the development of the disease [3]. However, the cause of this is not known. There is some evidence that there are mutations in genes regulating angiogenesis [4]. There is also evidence of increased expression of antigens associated with placental vessels in hemangioma [5]. The mechanisms underlying the spontaneous resolution of the disease is not well understood. A greater understanding of this process may also provide clues to the underlying pathobiology. There are many technical challenges of performing surgery on cavernous hemangiomas in the orbital region and therefore an understanding of the disease will help us to develop potential medical therapies, which may obviate the need to perform surgery.

\section{Abbreviations}

CT: Computerized tomographical; MRI: Magnetic resonance imaging; T1W: T1-weighted; T2W: T2-weighted

\section{Acknowledgements}

Not Applicable.

\section{Author's contribution}

$X P, R Z$ and $S L$ designed the paper, $L X$ collect the data, XP drafted the manuscript, QR, YF, HK, XL and GZ followed-up the patient, FA edited the manuscript. The author (s) read and approved the final manuscript.

\section{Funding}

This work was supported by the Science Foundation for Youth Scholars of Wuhan University (2042019kf0095), which from Fundamental Research Funds for the Central Universities and China Scholarship Council. The funding source had the role in design, execution and the decision to submit the manuscript for publication.

\section{Availability of data and materials}

The datasets supporting the conclusions of this article are included within the article.

\section{Ethics approval and consent to participate}

The procurement of this study was obtained with written patient-informed consent and approved by the Institutional Ethics Committee Faculty of Medicine at Renmin Hospital of Wuhan University.

\section{Consent for publication}

The patient agreed her medical records and images to be published. A written informed consent was obtained from the patient.

\section{Competing interests}

No conflict of interest exists in the submission of this manuscript. I would like to declare on behalf of my co-authors that the work described is original research that has not been published previously, and not under consideration for publication elsewhere, in whole or in part. All the authors listed have approved the manuscript that is enclosed.

\section{Author details}

'Department of Neurosurgery, Renmin Hospital of Wuhan University, 238 Jiefang Road, Wuhan 430060, Hubei, China. ${ }^{2}$ Massachusetts General Hospital Cancer Center, Harvard Medical School, Boston, MA, USA. ${ }^{3}$ Department Molecular and Cellular Biology, Harvard University, Cambridge, MA, USA. ${ }^{4}$ Department of Neuroscience, University of Cambridge, Cambridge, UK. ${ }^{5}$ Department of Neurology, Renmin Hospital of Wuhan University, Wuhan, China. ${ }^{6}$ Department of Gynecology and Obstetrics, Renmin Hospital of Wuhan University, Wuhan, China. ${ }^{7}$ Department of Orthopedics, The First Affiliated Hospital of Jinan University, Guangzhou, China. ${ }^{8}$ Department of
Neurosurgery, Tongji Hospital, Huazhong University of science and technology, Wuhan, China. ${ }^{9}$ Department of Anesthesiology, Cancer Hospital of Hubei Province, Wuhan, China. ${ }^{10}$ Department of Geriatrics, Renmin Hospital of Wuhan University, Wuhan, China.

Received: 29 October 2019 Accepted: 16 April 2020

Published online: 22 April 2020

\section{References}

1. Park $\mathrm{BH}$, Hwang $\mathrm{E}$, Kim $\mathrm{CH}$. Primary intraosseous hemangioma in the frontal bone. Arch Plast Surg. 2013;40(3):283-5.

2. Mulliken JB. Diagnosis and natural history of hemangiomas. In: Mulliken JB, Young AE, editors. Vascular birthmarks: hemangiomas and vascular malformations. Philadelphia: WB Saunders; 1988. p. 41-62.

3. Krowchuk DP, Frieden IJ, Mancini AJ, Darrow DH, Blei F, Greene AK. et al, Clinical practice guideline for the management of infantile hemangiomas. Pediatrics. 2019;(1):143, E20183475.

4. Boye E, Yu Y, Paranya G, Mulliken JB, Olsen BR, Bischoff J. Clonality and altered behavior of endothelial cells from hemangiomas. J Clin Invest. 2001; 107:745-52.

5. North PE, Waner M, Mizeracki A, Mrak RE, Nicholas R. A unique microvascular phenotype shared by juvenile hemangiomas and human placenta. Arch Dermatol. 2001;137(5):559-70.

\section{Publisher's Note}

Springer Nature remains neutral with regard to jurisdictional claims in published maps and institutional affiliations.
Ready to submit your research? Choose BMC and benefit from:
- fast, convenient online submission
- thorough peer review by experienced researchers in your field
- rapid publication on acceptance
- support for research data, including large and complex data types
- gold Open Access which fosters wider collaboration and increased citations
- maximum visibility for your research: over $100 \mathrm{M}$ website views per year
At BMC, research is always in progress.
Learn more biomedcentral.com/submissions 